\title{
Defining the Future: An Interrogation of Education and Time
}

\author{
Sandra Leaton Gray, Cambridge University
}

Published in British Journal of Sociology of Education, 25 (3 ), July 2004, 323-340

\begin{abstract}
This paper examines notions of 'educational time' with particular reference to the work of Basil Bernstein. It focuses closely on the 1967 Plowden Report as a particularly appropriate policy case study to demonstrate how different constructions of time can exist within the same document. It then develops educational models originally mapped out by Bernstein, arguing that a full understanding of the areas of consensus and conflict amongst these models is vital if we are to understand how teaching professionals think about the future. The paper addresses the following questions. How does time affect education? What influence does this have on educational outcomes? How does this relate to public policy initiatives? Assuming a tacit, collective understanding of time and the future can undermine the very policy intentions a government might be seeking to promulgate.
\end{abstract}

\section{Introduction}

Is time a socially constructed phenomenon? How different social groups conceptualise time is an interesting concept for investigation, not least because different conceptions can appear to coexist simultaneously. This can cause tension between different sectors of society. This paper considers the implications of such a phenomenon for education.

Government policy documents invariably invoke an account of education in time as a rhetoric device to legitimate educational change and convince others of the imperative need to change in the way being advocated. Today, much is made of the idea that education must adjust to the requirements of a new 'knowledge' or 'learning' society that marks a radical break with past times both socially and educationally. This type of historicist device is employed in virtually all major educational policy documents over the past fifty years. The Plowden report (1967) usefully reminds us that we have heard much the same kind of thing often before and this fact raises the issue of rhetoric and reality. The frequency of these urgent proclamations is such that if read sequentially such documents suggest that we have entered a new era in each decade of the past half century! The combination of urgency and the sense that there is no alternative, conveyed by such rhetoric, attempts to persuade us that this is the case. Additionally, it also obscures the fact that not everyone has the same understanding of what is meant by the term 'future', and it fails to take into account the very different ways that notions of 'time' affect education, in relation to the child and the acquisition 
of knowledge, for instance. This paper analyses these notions, and demonstrates that there are areas of consensus and conflict that can go unnoticed.

This paper explores the relationship between politics and time, with particular reference to the work of Basil Bernstein (2000). Plowden (1967) is taken as an exemplar for the purposes of this analysis. Plowden deals with time in relation to education in two main ways: time within the child, which is primarily a biological/cognitive function, and an historical, periodising time frame, which places schools and their pupils within a national, chronological framework. In addition, Plowden also has an existence in time through its longstanding influence and its symbolic role as a marker of 'progressivism' within the political and ideological discourses of education. The principle concern, here, is with the way in which time as a category (structured in different ways) might operate as a regulative device shaping educational discourses and practices in different ways.

On the basis of this initial analysis, a model is developed that demonstrates the ways in which 'education time' is presented and given ideological form in different educational discourses: neo-conservative traditional, modernist, progressivist, and generic. Each of these models tends to exist in different kinds of educational institutions or contexts. Depending upon which model is the primary one in use, there is a different emphasis on the role of knowledge. In some cases, for instance, knowledge is internalised, and part of the knower. In others, it is externalised, and the knower has to attempt to master it before moving on to other learning tasks.

\section{Time as a Social Construction}

There is a substantial and growing literature relating to society, education and time, as can be seen in the work of Adam (1990, 1995), Brannen (2002), Brannen and Nilsen (2002), and Petrie (1996), to mention a few of the more significant ones in terms of this paper. In the light of this, as a means of locating the research, it is useful to examine how history is divided into periods, as a way of looking at the social construction of time. This shows us how different groups conceptualise time, and how this relates to their notions of social order. It has the added advantage of demonstrating how notions of social order have changed, which is useful in understanding areas of consensus and conflict between those who draft education policy, and those responsible for education delivery.

A good example of the relationship between time and social order can be seen in the way we create organising categories for time. These are heavily influenced by culture. For example, dividing history into periods might at first seem to be fairly straightforward. One system could be to look at history century by century, for example. Although this system seems simple and easy to understand, it demonstrates the problem in deciding how to divide time. Certain time periods are based in nature, being cyclical and dependent upon movements of the planets. An obvious example of such time periods is the 24-hour day (one full rotation of the earth on its own axis), the month (lunar cycle), and the year (one full rotation of the earth around the sun). Such cyclical types of "time" appear prominently in pre-modern societies, and could be classified as "anthropological" time (Levi-Strauss, 1966, Alexander, 1995). Gellner (1992) describes this type of time as being a "train travelling across a faceless landscape", arguing that few distinguishing features existed to demarcate time to such 
pre-modern societies, which meant that they probably took little notice of time in general, apart from its effect upon the seasons, and life expectancy.

Other divisions of time are socially constructed by people. An example of this might be the week, which has no basis in nature. The century is also socially constructed. Hence dividing history into hundred-year groupings is essentially an artificial act. This gives an indication of the problems involved in trying to group historical events into "trends". As mentioned previously, the social and cultural environment of those undertaking the task necessarily influences any categorisation. For example, the "dreamtime" stories of indigenous Australians relate accounts of creation, and the "dreamtime" is described as being the "time before time", or the time before collective social consciousness. Those who are able to tell the story behind the creation of an area of land are traditionally its owners. This appears to be another type of what Alexander would call "anthropological time".

Later methods of periodisation involve different theories of development to describe and classify divisions of time. These might include large-scale, quasi-universal trends such as utopianism and declinism, or alternatively there might be an emphasis on national and international issues such as the reign of different monarchs, economic changes, or changes to political structures. As societies become more "modern", the pace of change appears to become faster and faster. Levi-Strauss (1966) described such periods as "hot" chronologies, as opposed to "cold" chronologies, when very little change appears to be taking place.

It is this last point, which is of most interest to us. Government invariably invokes a rhetoric of "rapid change" as a means of giving momentum to any policies. This is understandable, but such an approach can cause problems if the policy involves a proportion of "change for change's sake". The rest of the paper will explain this in more detail.

\section{Politics and Educational Time}

Since the introduction of universal primary education in Britain in the mid-19th century, constructions of "time" in education have traditionally been based on a range of different influences (Petrie, 1996) The rhythm of the school year provides a structure partially based on the natural environment. For example, the long summer holiday was originally provided so that rural pupils could assist with the harvest each year. There are religious demarcations, such as the Christmas holidays, Easter holidays, and a holiday at Whitsun in the spring (now incorporated into the Spring half-term). Finally, there are biological demarcations, such as the age pupils began school, the age of puberty (which had some influence historically on differential ages of school transfer for boys and girls in the independent sector), and the age at which they leave school to become economically active, to study further, or to fulfil some domestic role.

Additional influences have been added over the years. Examination timetables and school inspections have brought their own impetus. Schools no longer consist of one large mixed-age class, as pupils are divided into age-based cohorts instead. Over the last hundred years, schools have been presented with a major new education act roughly every generation (most recently in 1944 and 1988), and these have resulted in further notional "divisions", as people refer to periods "before" and "after" each act. 
Different reports, such as the Crowther Report (1959), the Newson Report (1963), and the Plowden Report (1967) have also caused further temporal "divisions". These serve as a means of periodising education, but their relationship to time is socially constructed. This is contrast to the Victorian education system, with its apparently greater concern for the natural environment and biological time.

Educationalists and policy makers additionally spend a great deal of time considering the future. At a classroom level, this might mean planning out a scheme of work or anticipating an examination syllabus. At school level, this might involve strategic planning work. At Local Authority level, it is important to anticipate local pupil numbers and the demands of the regional job market in years to come. At government level, national social and economic policy is at stake. We could continue to international levels with the same kinds of examples. Modern societies regard investment in the education of the young an important part of planning for the future, and thinking about education cannot be separated from broader thinking about social change.

Schools are seen as 'producing the future' and the rhetoric of 'youth as future' positions schools as forward-orientated institutions. This is demonstrated clearly in Hansard, for example, in statements such as 'The future of this country is with our children'; 'Education is a source of experience and emancipation for people. It is the source of their future well-being' and 'The Government are (sic) offering parents, teachers and governors a strategic and sensible vision of education for the future'. (Hansard 1995/1999).

There is a further continual need to control any possible disorder with motivational slogans such as 'Education 2000' and 'Goals 2000', implying urgency and a need for action. For example, the DfES attempted to raise the profile of mathematics through its 'Maths 2000' campaign, and developed the National Curriculum with a 'Curriculum 2000' programme. Time, it seems, is pressing. This relates to the notion of the "hot" chronology, as described earlier.

\section{Time in Education}

If we want to look at how the progression of time affects the organisation and structure of education, it is useful to examine Bernstein's later work. To place this work into context, he appears at the end of a century in which free universal secondary schooling was introduced, in the shadow of widespread reforms to social provision after the Second World War. Consequently there was increasingly a greater concern for the quality of education as opposed to the quantity. Bernstein wrote the work referred to here on the cusp of a change from a long-serving Conservative government to a Labour government. He considered that both governments had misunderstood the essential nature of education, and were pressuring the teaching profession to make unhelpful changes, which would prove to be inappropriate in the long term. His was writing a generation after the Plowden report (1967), which will be referred to in detail later. This report had substantially influenced his ideas.

Bernstein argues that there is a type of social grammar behind pedagogic communication that is often ignored in favour of the content of such communication. Bernstein (2000) identifies three sets of rules regulating pedagogic communication: 


\section{Distributive Rules}

These rules regulate the relationships between power, social groups, and forms of consciousness and practice. They map out the way education fits into, and reflects, society and regulate the division between the thinkable and the unthinkable, the esoteric and the mundane, what is possible and the possibility of the impossible. For present purposes, this is important, because any speculation about the future of education takes place in the discursive gap between the two polarised viewpoints.

An example of this might be contrasting ways that we make assumptions about the future existence of schools as physical and institutional entities. Many people assume that schools will continue to exist. Any alternative is "unthinkable". The existence of schools should not be taken for granted, however. In the course of my research, which examines professional conceptions of the future of education, many teachers have questioned the continuing existence of schools, and speculated about the likely increase in distance learning facilities as a substitute for the traditional model of the school. These teachers are therefore "thinking the unthinkable", by challenging existing orthodoxies.

\section{Recontextualising Rules}

The rules regulate the form of the educational discourse, defining who can transmit what, and to whom. These rules are concerned with the transmission of skills as opposed to the transmission of values, and govern sequencing and pacing of educational delivery.

Often these rules are regarded as being fixed by education providers. There is an assumption that children go to one school at certain times of the day, to learn discrete subjects from teachers who are, by nature of their professional appointments, not practitioners in any field other than education. Challenging the assumption that this is the 'norm' is a theme that raises its head throughout any kind of Education Futures research, as mentioned above.

Taken for granted assumptions about what constitutes 'skills' and what constitutes 'values' can create contradictions between the overt and the covert. A school might teach one thing in its personal and social education lessons, and yet transmit quite another message as part of its hidden curriculum. For example, it may overtly try to promote racial equality, yet it may have no ethnic minority members of staff, and make no particular attempts to recruit any.

\section{Evaluative Rules}

These rules provide the nuts and bolts of pedagogic practice and it is here that Bernstein considers the crucial relationship between 'space', 'time' and 'text'. 'Time' is the arbitrary age stages that are used to punctuate the pedagogic process, 'text' is the specific content of the pedagogic device, and 'space' is the specific context of the pedagogic device. Where these rules are strongly classified, assumptions about the age at which children start and finish school, and the 'stages' through which they pass during their school journey, are clearly demarcated and relatively strictly adhered to, 
whether or not this is suitable for a particular child. To challenge the validity of such timing is to 'think the unthinkable' once again.

In certain types of educational regime, the child's capacity to acquire knowledge at the correct pace is often considered to be a measure of ability, and this operates as what Bernstein terms a 'symbolic ruler' measuring consciousness in terms of synchrony (Bernstein, 2000 p. 202). In this way, time is used to differentiate between the normal and abnormal child, providing models for the teacher to work with. Unfortunately this presents practical difficulties. It can be noted here that whereas in 'traditional' education the measure of time is external to the child in a preordained sequencing of knowledge (essentially the ruler is the syllabus) in 'progressivism it is 'internal' as part of the child's nature (see below on Plowden). The top and bottom of the ability bands have difficulty conforming to a rigid temporal framework, and may need to be 'outside time', working at a different pace. This can also lead to geographical or spatial changes for the child, as he or she is removed to a special unit, perhaps, or transferred to work with another age group. In this type of measurement, some children come to be labelled 'slow' and others are forced to slow down or 'shrink to fit' an educational model unsuitable for their needs, 'inclusion' being all.

For the 'slow' child, this might mean the apparently fruitless exercise of trying to achieve Level One of Key Stage One of the UK's National Curriculum having had half the full-time schooling of classmates thanks to a summer birthday. For the gifted child, this might mean waiting for the rest of the class to catch up, being restricted in opportunities to answer questions or make points in whole-class discussions, or being obliged to stay with their chronological age group for all lessons, regardless of their level of subject attainment.

Indeed, there has often been suspicion of deviation from a perceived temporal 'norm'. For example, the one initiative that might have been of value to both fast and slow learners in the 1960s and 1970s at primary school, the Initial Teaching Alphabet (ITA), was eventually dismissed after it was decided that there was no noticeable improvement in reading speeds in the 'average' child. This was despite the fact it had clearly assisted literacy development in 'fast' and 'slow' learners (Warburton and Southgate, 1969).

\section{FIGURE 1}

Alternative educational models deal with this in a different way. Plowden (1967) demonstrated a more 'bespoke' type of education, with a post-Froebelian, childcentred approach to primary education and the gradual horticultural 'unfurling' of the child's abilities in contrast to the more 'mechanistic' curriculum ordered approach. A more detailed examination of Plowden can both illustrate the above points and illustrate their broader, contemporary application.

\section{The Plowden Report (1967)}

The Plowden report gives a detailed account of English Primary School teaching in the 1960s, and includes recommendations and conclusions. It reflected current practice, but also developed two key concepts: the need for positive discrimination and Educational Priority Areas, and the importance of productive home-school 
relationships. Plowden clearly reflects a dominant ideology of education in which the child was placed firmly at the centre. It is not for nothing that the title of the report is 'Children and their Primary Schools'. Plowden was written in an age that saw the end of selective secondary education in many areas, to be replaced by comprehensive provision. It pre-dates the National Curriculum and Standard Assessment Tests, which tie children to particular nationally set targets of achievements. This positioning allows an individualistic, flexible notion of time to influence policymaking.

This analysis will confine itself to examining how the Plowden report deals with the concept of time. Plowden looks at 'time' in two ways. There is time within the child understood in developmental terms and as the guide to how to teach, and the historical flow of time within which education is located and to which it must respond: time in education and education in time.

Time within the Child: With regard to the former, in Chapter Two, Plowden gives a detailed analysis of children's growth and development, and the sequences in which this occurs. Growth charts are included, and there is emphasis upon the different rates at which children develop as adolescents. There is a long section on the growth of the brain, both physiological and psychological, with reference to the work of Conel on sequential development, and Piaget and Inhelder on the emergence of mental structures. The section describing the interaction of heredity and environment gives a fascinating account of the role of genetics in child development. Much of this appears to remain relevant today, even though research into the human genome has progressed dramatically since 1967. There are sections on the development of behaviour, language, and the emotional development of the child. These also have contemporary relevance. The chapter concludes with recommendations that assert that children need to be regarded as individuals rather than a collective entity.

\section{Historical Time:}

The theme running through Plowden is one of 'progress' as opposed to 'retardation', providing legitimisation of any educational change. For example

"In villages accessible to towns where the occupational distribution is changing, the children's attainment may also be expected to change. Some country people speak less and speak more slowly than people in town. It may be that country children have have been handicapped by silence at home ..." (Plowden, p. 177, para. 478)

"Children living in new houses often go to new schools. Yet children left behind in the decaying centres of large towns attend schools that often match their environment." (Plowden, p.390, para. 1083)

The emphasis, as far as "historical" time is concerned, is on the effect of the external environment on pupils. The discourse employed by Plowden when describing schools is particularly of interest in this respect.

\section{TABLE 1}

When making a case for Education Priority Areas, an almost Dickensian image is painted of neglected, urban schools, on cramped sites, marooned by the heavy traffic 
surrounding them. The schools suffer from poor sanitation and heating facilities, and are noisy, dark and grim. Such bleak observations are reminiscent of the Hadow report (1931), which referred to deprived and undernourished children with "pinched faces".

The neglected urban schools of the Plowden report are described as being "behind the times" (Plowden, p.50, para. 133). In contrast to this, the "modern" school is light, bright, and friendly. It tends to be situated in a suburban location, domestic in character, with plenty of lavatories and hot water. Children are encouraged to move around the building to work in large and small groups, using attractive learning resources to establish lifelong interests and skills. This "modern" school is how Plowden categorises contemporary, progressive learning (Plowden, p.396, Diagram 8, Finmere School, Oxfordshire).

The same process of analysis is applied to children and their families. However the Plowden report attempts to be more diplomatic in its classification of the differences between backgrounds, and references to social class are rare. The terminology is indicative of this.

\section{TABLE 2}

Developing the concepts expressed in table 2 above, there is scope for a deeper level of analysis. The notion of retardation in Plowden appears to resemble Bernstein's theory of restricted code. This is particularly obvious in the reference to rural speech patterns "handicapping children", as quoted above. Urban families, on the other hand, are reported to speak more quickly and more often. Such families seem to represent an "ideal type", in terms of Plowden. Their elaborated code allows them to be supportive of the teachers' (middle class, urban) ideals, communicating well with the teachers. Their apparently superior use of speech at home allows them to hand this inheritance on to their children. However, adherence to the theory of restricted and elaborated code is problematic. It is assumed by Plowden that rural families, large families, and immigrant families, amongst others, are unlikely to be able to offer educational advantages to their children.

\section{Conclusion:}

I have demonstrated that the Plowden Report is a good example of how policy documents can contain internal inconsistencies to do with time, which can affect the success of any policy implementations. On the one hand, it argues that time is inherent within a child, and primarily dictated by genetics and physiological developments. On the other hand, it argues equally forcefully that parental attitudes affect rates of progress and the age at which pupils choose to leave school. (In this way, Plowden neatly skirts the issue of how social class affects education, emphasising 'attitudes' instead). Yet these issues are still important, so it uses language laden with references to 'time' - schools with buildings over a century old are described as 'left behind', for example, as are their surrounding communities. Families that fail to conform to the notion of an "ideal type" are labelled with terms such as "retardation", whereas the white, Anglo-Saxon family with two or three children is promoted as a "progressive" model. 
Real-life situations, of course, are not as polarised as the contents of Plowden, as described above, suggests. Bernstein developed three educational models that look at these possibilities in more detail, and with greater complexity. I will now discuss and adapt these models for the purposes of this analysis, turning attention to conflicts existing within the role of the teacher in relation to time.

\section{Time and Education}

As demonstrated in the Plowden Report, education is not just regulated by 'internal' time. It is discursively located within broader accounts of historical and social change. As stated above, these discourses of change are a major source of the rhetoric that attempts to empower the ideology of educational reform policy. The question is how best to classify these discursive forms. Bernstein maps three models for education: the competence model, the performance model, and the generic model. He compares and contrasts these models, and relates them to different identities within the models themselves. Table 3 is a table that lists the salient characteristics of each model.

\section{TABLE 3}

Each model represents time in a particular way. In some cases, different models are used at different stages of education ${ }_{2}$ and some have a more fluid approach to delivery than others. There are also similarities between certain of the models as well as differences, for example, both the performance models and the generic models pay less attention to the past, and look forward to future competence, though they differ in other respects. The performance model delivers a canon of knowledge that is subject to external evaluation and validation, whereas the generic model is a more therapeutic, pupil-centred approach to learning. Another way of classifying these differences might be externalised knowledge (in the case of the performance model) and internalised knowledge (in the case of the generic model).

Conflicts between the models are rife, however. The most significant aspect is that there is no consensus as to the purpose of education. Is it therapeutic, a filtering process for higher education levels, or is it a Fordian production line creating workers for the future? Or is it each of these things? Conflict here is endemic.

There are also fundamental conflicts in defining the function of the teacher. Is he or she an artisan, a facilitator, a technician or an advanced practitioner? Again, there is uncertainty as to the nature of the professional role. The definition of function in this case varies according to which educational model is being used. The "facilitator", delivering a carefully crafted holistic pedagogy to primary schoolchildren, differs enormously from the experienced manual labourer passing on the skills of the trade at a Further Education college. These are intrinsically irreconcilable differences in approach. Similarly each type employs different types of criteria for determining the success of the educational process. This could take the form, for instance, of a quasispiritual awareness, shared between teacher and pupil of potential having been fulfilled or by the meeting of targets set by external authorities. The reality is that learners will engage with different "types" of teacher at different points in the learning process. However, whereas teachers and learners appear to understand that there is a diversity of provision in this way, Government policy appears confused about the existence of radically different teaching models. The same regulatory structure is applied indiscriminately to every educational situation. This means that nursery 
nurses are expect to perform in the same way as secondary school science teachers, and hobbyists teaching craft for an hour or two a week at evening classes.

If we agree that there is considerable confusion, one important fact looms into better focus from the table, which is connected to a larger concept of erosion of the professional autonomy of teachers, and changes to their professional identities. As far as our purposes here are concerned, however, we need to start by looking at the different roles of teachers and pupils in relation to the curriculum and its delivery, before we can delve any further.

The 'performance' model which influences contemporary education policy is, in many senses, 'retrospective' in Bernstein's terminology. This might appear to contradict the statement that it regards 'past as invisible', as represented in the diagram, but this is not the case. The past is only invisible to the pupil and teacher engaging in a pedagogic exchange. The model itself, however, is backward looking in the sense that it relies on a tight structure of educational sequencing and pacing, which is monitored rigorously. This is in direct conflict with the spirit of adventure and entrepreneurism that is expected of schools managing their own affairs. If teachers desire a degree of autonomy to allow them to make changes in accordance with their mental models of the future, and they are prevented from doing so by a performance-based educational model, then there is bound to be a degree of professional frustration, as can be shown in figure 2 .

\section{FIGURE 2}

This raises further questions to do with teacher professionalism. If the definition of a professional includes the ability to manage one's own time, there is currently a paradox. Contractually teachers are usually employed upon the basis of a specified amount of 'directed time' to be spent on set tasks dictated by the needs of the National Curriculum and the Head Teacher. This undermines teacher autonomy, and results in a shift in the social relationship between professional status and time management. The issue of time management is central to the definition of professionalism, and the issue of time in education is as important for teachers as it is for pupils. In general terms, in any society, the greater scope that groups have to manage their own time rather than have it managed by others, the higher the status. As lower status work is often associated with the notion of directed time, such contractual 'agreements' have the effect of deprofessionalising teachers. Here there is a potential for division. Some teachers will accept this external regulation of time, perhaps by a redefinition of their professionalism, whereas others are likely to be offended by the assumption that they are not capable of managing time effectively themselves.

Looking at this loss of status, we can see that there are important changes taking place, with a shift from 'invisible' or internalised to 'visible' externalised modes of regulation of teachers' professional activities. External control, with rigidly set criteria for assessment and targets, means that it is easier to measure an outcome and therefore have quantifiable evidence that 'progress' has occurred. For this type of system, a new, different type of teacher is required: one who is obedient to a particular type of educational model, involving a great degree of external control. This moves away from the notion of internalised regulation through the formation of 'habitus' in which a teacher develops an inner 'compulsion' to carry out professional 
activities in a certain way. In external regulation we see a simplification of tasks so that they can be easily measured. In the next section we now need to classify and analyse the situations in which these changes occur, by developing Bernstein's models into a more complex structure.

\section{Developing Bernstein's Models}

As stated previously, Bernstein has mapped out three strictly defined educational models - "competence", "performance" and "generic". However, he has also described how these models can vary according to the social and cultural situation surrounding the educational model (Bernstein, 2000, pp. 65-79). He refers to these variations as "modes". This is a very useful way of describing how the models apply in practice. For present purposes, this is interesting, as it allows us to see how the different educational models position themselves within time, according to the external environment. This next section will explain how this positioning occurs, and give some examples.

To do this, it is useful to develop a modified structure of Bernstein's work. For the purposes of this dissertation, the "performance" modality has been subdivided to allow for two different modes - "neo-Conservative traditionalism" and "modernisers". These two modes position identities differently in time. Neo-conservative traditionalists look backwards to a restorationist "golden age" of education, whereas modernisers look forward to an employment-orientated "instrumental age" of education. This is of such significance to my investigation of time in relation to education, that I have reclassified these as new "models" as a way of emphasising their importance. If we allow Bernstein's models to evolve into four over-arching educational 'types', as I have done here, we begin to see areas of consensus and conflict amongst models, which start to explain why there can be difficulties reconciling policy and professional action at different levels.

I will now analyse each of these areas in more details to clarify where the areas of consensus and conflict occur, and in doing so explain why four models are needed. The descriptions below employ the terminology standard in this literature.

\section{Neo-conservative Traditionalism}

Generally found in the Secondary (particularly independent) and Higher Education sectors, this model relies on subjects being taught as discrete entities, by a teacher who exercises considerable authority over the content and delivery of the curriculum. Each subject is seen as taking a place within a strict hierarchy, with a corresponding hierarchy of intellectual 'stages' that must be travelled through in order to reach a level of competence. The timescale for this development is largely irrelevant. Each subject is composed of a series of finite, eternal truths, which need to be learnt.

This educational model shares an idea with the 'Performance' or 'Modernisers' model of education. It regards the idea of a fixed body of knowledge that needs to be acquired as tantamount. However it differs in one important way from the 'Performance' model. It does not regard ease of access to this body of knowledge as being important, nor does it seek to undertake quantitative measurement of such knowledge. In this way it is in conflict with the aims and ideals of the National Curriculum. 


\section{FIGURE 3}

Both the 'Progressive' and 'Generic' models consider themselves to be 'outside time', requiring pupils to work at an individual pace rather than being tied to any chronological timeframe. Hence in the independent sector, we see GCSE examinations being taken earlier or later than the usual age of sixteen, according to the needs and abilities of individual pupils. In the maintained sector, however, this tends to be discouraged on two grounds: difficulty in planning teaching schedules accordingly, and the fact that any 'early' or 'late' GCSE results will not appear in the Government league tables for sixteen-year-olds.

\section{Modernisers}

This model is most prevalent in the Secondary sector, although it is increasingly evident in the late Primary sector as a result of the introduction of Standard Assessment Tests at the ages of 7 and 11. It shares the idea of a fixed body of knowledge with the Traditionalists, as discussed above, but differs in that the body of knowledge is tightly prescribed, in the form of the National Curriculum, with the teacher acting more as a technician rather than an autonomous entity. The education is clearly fixed in time, with age-related targets and quantitative measurement of their achievement. 


\section{Progressivism}

Adapted from Bernstein's 'Competence Model', this model relies on a fluid body of knowledge, with the learner at the centre. The teacher is autonomous, and interprets the needs of the learner through a device such as the Plowden report. As previously discussed, the educational model lies outside historical time, with a 'bespoke' education being tailored to the needs and abilities of each individual pupil. It could be regarded as anti-academic in the sense that it does not embrace a clearly defined subject hierarchy, and the emphasis is on learning as opposed to progressing through stages of understanding of specific subject content. In other worlds, the focus is on 'doing' rather than 'reaching'. The anti-academic nature of this model, and its focus on the learner, are both aspects that are shared with the 'Generic' model.

\section{Generic}

This model is predominantly found in low-level vocational training and the Further Education sector. Like the 'Progressive' model, it has the learner at the heart of its purpose, and offers a skills-based approach to study. It stresses the importance of experience, and consequently the teacher is regarded as a 'senior learner'. In common with the Traditionalists and the Progressives, it lies outside time, as pupils access the education as they need it, and at their own pace. It offers the opportunity for flexible specialisation so important to the modern economy (Young, 1996).

When there are attempts to describe changes in the national economic structure, the term 'knowledge economy' is widely used. Many assumptions are made about the meaning of the word 'knowledge' in this context. Yet there has been no attempt to define the term exactly. The four models above go some way towards this. However if we are to understand the concept of knowledge adequately, the definition needs to be further broken down, as can be seen in figure 4. This figure attempts to differentiate between internalised and externalised bodies of knowledge, as well as knowledge that exists in its own right as opposed to practical, or applied, knowledge.

\section{TABLE 4}

This now needs to be explained in greater detail.

The Neo-conservatives regard knowledge as a canonical body, which is handed down more or less intact from teacher to pupil. This is an example of how knowledge can be regarded as 'sacred' and externalised, existing in its own right. The Modernisers also use a form of knowledge that exists externally, but one that has greater practical application, being geared to the needs of industry and the national economy. Progressivism, on the other hand, uses a form of knowledge that unfolds from within the self. The Generic model uses the same internalised form, but as it is competencebased, it has the same practical application seen in the case of the Modernisers.

It is significant that the Neo-conservatives and the Modernisers both see knowledge as externalised. Beck (1999) argues that the New Labour government's educational agenda has much in common with the previous New Right administration. There has been a quest to reduce the autonomy of educational institutions over the last quartercentury, as a result of the policies of both Labour and Conservative governments. This 
has eroded a tradition of 'scholarship', leading to a more utilitarian approach to education (Bernstein, 2000).

\section{Conclusion}

This paper argued that it is important to understand the context in which teachers, pupils and policymakers think about the future. The paper was initially placed in historical and sociological context in relation to the sociology of time. It then stated that education policy often fails to take into account the different ways that time affects pedagogic communication. It examined Bernstein's work in this area in considerable detail. He defines clear rules for any pedagogic communication or device. The paper argued that if we examine these rules, we see that there are areas of consensus and conflict that relate to the concerns of education professionals when they think about the future. It then used the Plowden report, with its references to biological and historical time, to provide an example of how contradictions of this kind can exist within a policy document, causing potential problems with any implementation. It examined Bernstein's models for education, and developed his ideas to include four, rather than three models, to illuminate subtle political differences between educational models and their related discourses. These discourses varied from ones involving an externally configured definition of knowledge, to a holistically configured definition, grounded in the individual needs of the learner. The existence of these models is readily apparent to those engaged in education. Yet it is not accommodated sufficiently within policy documents.

The paper argued that again, amongst these four models, we could see areas of consensus and conflict that provided the backbone of much speculation to do with the future of education: whether schools as institutions will continue to exist, whether technological innovation will revolutionise the learning process, and so on. This paper has therefore produced a tentative explanation of the way in which the future occurs, as well as the areas of concern that are most likely to appear in any discussions with educational professionals. This is vitally important, because if there is no acknowledgement of the role of time in education, then there can be no useful progress towards adapting current teaching methodologies and educational structures to future social climates. The reality is that learners engage with different educational models at different points in their careers, and unless this complexity is recognised in future policy strategies, opportunities to craft increasingly sophisticated and relevant learning environments will have passed us by.

\section{Sandra Leaton Gray}

Faculty of Education, Cambridge University, 17 Trumpington Street, Cambridge, CB2 1QA. 


\section{References}

ADAM, B

ADAM, B

ALEXANDER, J C

BERNSTEIN, B.

BECK, J.

BRANNEN, J and

NILSEN, A

CACE

GELLNER, E
(1990) Time and Social Theory (Cambridge, Polity Press)

(1995) Timewatch: The Social Analysis of Time (Cambridge, Polity Press)

(1995) Fin de Siècle social theory: relativism, reduction and the problem of reason (London, Verso)

(2000) Pedagogy, Symbolic Control and Identity: Theory, Research, Critique (London, Taylor and Francis)

(1999) Makeover or Takeover? The strange death of educational autonomy in neo-liberal England, British Journal of Sociology of Education Vol. 20, No.2, June 1999

(2002) The work-family lives of women: autonomy or illusion? (Working paper, Gender Institute/ESRC "Work, Time and Life in the New Economy" Seminar series, 25 October 2002)

(2002) Young people's time perspectives: From youth to adulthood Sociology Vol 36, No 3 pp. 513-537

(1967) Children and their Primary Schools (Plowden) (London, HMSO)

(1992) Postmodernism, reason and religion (London, Routledge)

HANSARD (1995) Michie, Bill (Labour MP for Sheffield Heeley) 09/02/95

(1999) Gordon Marsden (Labour MP for Blackpool South) 02/03/99

(1999) Helen Jones (Labour MP for Warrington North) 11/03/99

HADOW

LEVI-STRAUSS, C PETERS, R S

PETRIE, $\mathrm{P}$

WARBURTON, F.

(1931) Report of the Consultative Committee on the Primary School (London, HMSO)

\& SOUTHGATE, V. (1969) i.t.a: An Independent Evaluation(London, Murray)

YOUNG, M.
(1996) A Curriculum for the Twenty-First Century? Towards a new basis for overcoming academic/vocational divisions, in: AHIER et al (Eds) Diversity and Change: 
Education, Policy and Selection (Routledge, London) 
Figure 1 The relationship of scholastic ability to a supposedly normative perception of 'time'.

\begin{tabular}{|c|c|c|}
$\begin{array}{c}\text { SLOW CHILD } \\
\text { 'Hurry them on' }\end{array} \stackrel{\begin{array}{c}\text { FAST CHILD } \\
\text { 'Shrink them to } \\
\text { fit' }\end{array}}{\text { Central 'inclusive' zone }}$ \\
\hline
\end{tabular}


Table $1 \quad$ Terminology used by the 1967 Plowden report in relation to age of school buildings.

\begin{tabular}{|l|l|}
\hline Old Buildings & New Buildings \\
\hline Grim approaches & Friendly \\
\hline Noisy & Domestic in character \\
\hline Dark & Light \\
\hline Little play space & Outdoor areas part of school experience \\
\hline Near roads & Gardens \\
\hline "Ingrained grime of generations" & Modern \\
\hline Poor sanitation and heating & Good hygiene \\
\hline Cramped & Flexible use of space \\
\hline Urban decay & Suburban development \\
\hline
\end{tabular}


Table 2 Terminology used by 1967 Plowden report in relation to home backgrounds of pupils

Retardation Progression

\begin{tabular}{|l|l|}
\hline Lack of parental support for learning & Supportive parents \\
\hline 4+ children in household & Few children in household \\
\hline Poor/deprived home & Comfortable home \\
\hline Father is unskilled labourer & Father is professionalmanagerial \\
\hline Few books in household & Five or more books in household \\
\hline Parents reluctant to visit school & Frequent contact with school \\
\hline
\end{tabular}


Table 3

Bernstein's three models for education, compared and contrasted with special reference to time.

\begin{tabular}{|l|l|l|}
\hline Competence Model & Performance Model & Generic Model \\
\hline 'Progressive' & 'Back to Basics' & 'Creating workers' \\
\hline $\begin{array}{l}\text { Emphasis on personal } \\
\text { development/therapeutic } \\
\text { content }\end{array}$ & $\begin{array}{l}\text { External testing and } \\
\text { monitoring }\end{array}$ & $\begin{array}{l}\text { Located outside pedagogic } \\
\text { fields. }\end{array}$ \\
\hline Focused on the present & Focused on the future & $\begin{array}{l}\text { Focused on the present and } \\
\text { future }\end{array}$ \\
\hline $\begin{array}{l}\text { Tends to be used in primary } \\
\text { education or 'repair' } \\
\text { situations }\end{array}$ & $\begin{array}{l}\text { Tends to be used in } \\
\text { secondary education }\end{array}$ & Tends to bed in FE \\
\hline Future invisible & Past invisible & Past invisible \\
\hline Teacher interprets progress & Grades signify progress & $\begin{array}{l}\text { Task competence signifies } \\
\text { progress }\end{array}$ \\
\hline Teacher autonomy & Teacher as technician & Teacher as senior learner \\
\hline
\end{tabular}




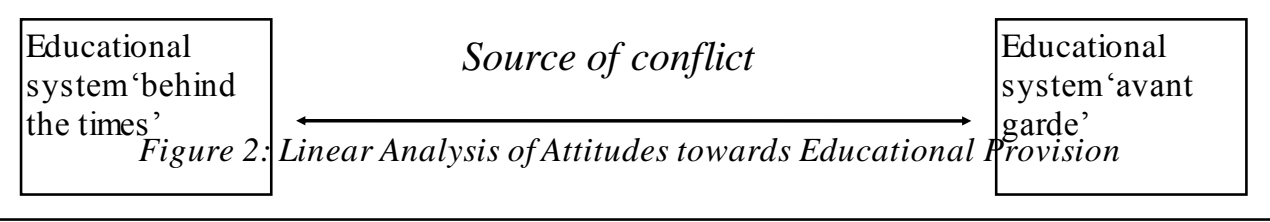




\section{Figure 3}

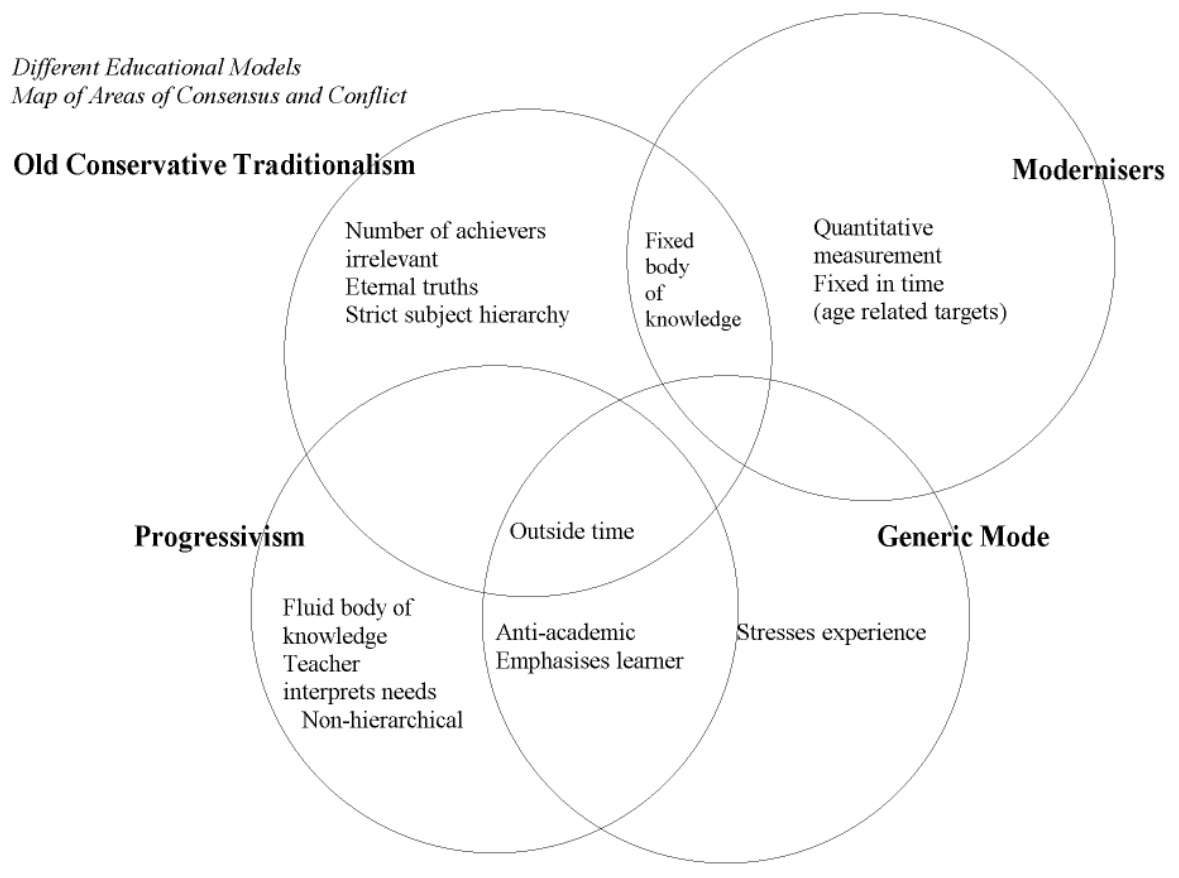


Table 4

Different categories of 'knowledge'

\begin{tabular}{|l|l|l|}
\hline \multicolumn{2}{|c|}{ 'Sacred' knowledge } & 'Profane' knowledge \\
\hline 'Outer' knowledge & $\begin{array}{l}\text { Neo-conservative } \\
\text { Traditionalism }\end{array}$ & Modernisers \\
\hline 'Inner' knowledge & Progressivism & Generic \\
\hline
\end{tabular}

